\title{
Coupling global chemistry transport models to ECMWF's integrated forecast system
}

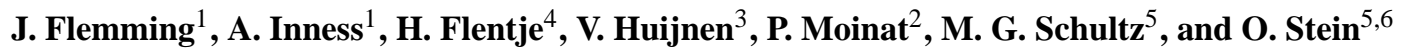 \\ ${ }^{1}$ European Centre for Medium range Weather Forecasting, Reading, UK \\ ${ }^{2}$ Météo-France, Toulouse, France \\ ${ }^{3}$ Royal Dutch Meteorological Institute, De Bilt, The Netherlands \\ ${ }^{4}$ Deutscher Wetterdienst, Hohenpeissenberg, Germany \\ ${ }^{5}$ Institute Of Chemistry And Dynamics Of The Geosphere (ICG), FZ Jülich, Germany \\ ${ }^{6}$ Max-Planck-Institute for Meteorology, Hamburg, Germany
}

Received: 19 June 2009 - Published in Geosci. Model Dev. Discuss.: 7 July 2009

Revised: 16 November 2009 - Accepted: 23 November 2009 - Published: 8 December 2009

\begin{abstract}
The implementation and application of a newly developed coupled system combining ECMWF's integrated forecast system (IFS) with global chemical transport models (CTMs) is presented. The main objective of the coupled system is to enable the IFS to simulate key chemical species without the necessity to invert the complex source and sink processes such as chemical reactions, emission and deposition. Thus satellite observations of atmospheric composition can be assimilated into the IFS using its 4D-VAR algorithm. In the coupled system, the IFS simulates only the transport of chemical species. The coupled CTM provides to the IFS the concentration tendencies due to emission injection, deposition and chemical conversion. The CTMs maintain their own transport schemes and are fed with meteorological data at hourly resolution from the IFS. The CTM used in the coupled system can be either MOZART-3, TM5 or MOCAGE. The coupling is achieved via the special-purpose software OASIS4. The scientific integrity of the coupled system is proven by analysing the difference between stand-alone CTM simulations and the tracer fields in the coupled IFS. The IFS concentration fields match the CTM fields for about $48 \mathrm{~h}$ with the biggest differences occurring in the planetary boundary layer (PBL). The coupled system is a good test bed for processoriented comparison of the coupled CTM. As an example, the vertical structure of chemical conversion and emission injection is studied for a ten day period over Central Europe for the three CTMs.
\end{abstract}

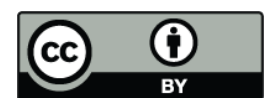

Correspondence to: J. Flemming (johannes.flemming@ecmwf.int)

\section{Introduction}

Routine exploitation of space-born observations of the atmosphere has been a major contribution to the improvements in numerical weather prediction (NWP) over the last three decades. Inspired by the success of satellite data assimilation in NWP, the "Global and regional Earth-system Monitoring using Satellite and in-situ data" (GEMS) project aims to routinely assimilate satellite observations in order to deliver re-analyses and forecasts of atmospheric composition (Hollingsworth et al., 2008).

The global component of the GEMS system has become part of the integrated forecast system (IFS) of the European Centre for Medium Range Weather Forecast (ECMWF), thereby benefiting from ECMWF's infra-structure for operational satellite data assimilation, weather forecasting and high-performance computing. To enable the IFS, which has until recently been a meteorological model system, to also forecast atmospheric composition, the simulation of emissions, chemical conversion and deposition had to be accounted for. The approach taken for the treatment of reactive gases is presented in this paper.

The forecast and assimilation of global reactive gases are performed by a two-way coupled system, which links the IFS to one of the global chemistry transport models (CTMs), MOCAGE (Josse et al., 2004; Bousserez et al., 2007), MOZART-3 (Kinnison et al., 2007) or TM5 (version KNMI-cy3-GEMS, Krol et al., 2005). Three candidate CTMs were selected because previous model intercomparison studies showed a considerable spread of results. A threemodel ensemble can provide some guidance with respect to

Published by Copernicus Publications on behalf of the European Geosciences Union. 
the robustness of the simulation results. Furthermore, the three candidate CTMs used different coding techniques for parallelisation and more than one option should be available in case of severe performance problems on the ECMWF computer systems. The simulation of global aerosol and greenhouse gases, which have been directly integrated into the IFS source code, is described in Morcrette et al. (2009) and Engelen et al. (2009).

The GEMS requirement was to couple the IFS to comprehensive non-linear chemistry schemes for the troposphere and stratosphere. Now completed, the IFS can simulate the species included in the CTM's chemical scheme. However, very short lived species such as the hydroxyl radical $(\mathrm{OH})$ are not suited for the coupled approach because its typical time scale is less than the coupling interval of one hour. On the other hand, the coupled system seems to be not computational efficient enough for the simulation of very long lived species such as methane. A parameterisation of the chemical conversion as integrated part of the IFS is a more efficient solution in this case. So far, simulation and assimilation experiments of tropospheric and stratospheric $\mathrm{O}_{3}$, carbon monoxide $(\mathrm{CO})$, nitrogen oxides $\left(\mathrm{NO}_{\mathrm{x}}\right)$, formaldehyde $(\mathrm{HCHO})$ and sulphur dioxide $\left(\mathrm{SO}_{2}\right)$ have been carried out with the coupled system. These species play a key role in atmospheric chemistry and are observable from space (Singh and Jacob, 2000). Examples of the assimilation of these species with the coupled system are given in Inness et al. (2009).

The idea of the coupled system is that the IFS computes only the transport of the reactive gases while the tendencies due to chemical conversion, deposition and emission injection are provided by one of the coupled CTM. The CTM itself is driven by meteorological data which are transferred at high temporal resolution from the IFS to the CTM. For example, the call of a subroutine for chemical conversion in an integrated chemistry-global-circulation-model code is substituted in the coupled system by a call to the coupler software requesting the respective total tendencies from the CTM. The tendencies are then applied to the concentration fields in the IFS at every time step to account for the local concentration changes.

The motivation to build a coupled system, rather than directly integrating the respective modules in the IFS code is elaborated in Sect. 2.1. Key reasons were the flexibility to apply more than one CTM for the provision of sink and source terms and the reduced development effort.

A potential problem of the coupled approach is that the chemistry and deposition tendencies applied to the IFS concentrations are calculated using the concentration fields that were calculated in the coupled CTM, which uses its own transport, convection and turbulent diffusion scheme. The transferred CTM tendencies can therefore be dislocated from the IFS concentration fields to which they are being applied. The dislocation can occur because of (i) the transformation between the CTM and IFS model grids by the coupler software, (ii) the differences between the concentration fields of the CTM and of the IFS due to a different transport simulation, (iii) the coupling interval of one hour being longer than the model time step, and (iv) an accumulation of dislocation errors in previous time steps. The dislocation error will be small if the source and sink tendencies are small in relation to the concentration values, i.e. for long lived species, and if they are small in comparison to the tendencies due to transport processes, i.e. for species with smooth spatial gradients. This paper will show that the IFS concentration fields in the coupled system are scientifically sound and correctly reproduce the simulation results from the CTM.

The remainder of the paper is structured as follows: the system components, the different application modes and the computational performance are described in Sect. 2. Section 3 comprises the test of the scientific integrity of the system, which investigates the impact of dislocation. Also included in this section is a comparison of the vertical structure and magnitude of tendencies due to emission injection and chemical conversion over Europe, which helps to give a better understanding of characteristics of the three CTMs. A summary concludes the paper.

\section{Description of the coupled system}

\subsection{Motivation for the design of a two-way coupled system}

An extension of an earth-system model can follow two approaches: (i) directly integrating subroutines or modules in one unified model or (ii) coupling independent models by means of dedicated coupler software. Direct integration often referred to as on-line coupling - is normally pursued when complex chemistry schemes are included in meteorological models. Examples of the on-line integration of chemistry modules in weather forecast models are GEM-AQ (Kaminski et al., 2008), GEMS-BACH (Ménard et al., 2007), WRF/Chem (Grell et al., 2005) and ECHAM5-HAMMOZ (Pozzoli et al., 2008; Rast et al., 2008). Zhang (2008) gives an overview of on-line coupled meteorology and chemistry models with a focus on the modelling of aerosol and cloudaerosol interactions. An interface standard for the on-line integration of earth-system models which can also include chemistry modules is MESSy (Jockel et al., 2006).

Coupling independent models with coupler software is often applied when the models cover different domains of the earth-system such as ocean and atmosphere. Ford and Riley (2002) present coupler software developed in North America and Europe. An example of the coupled approach in atmospheric chemistry modelling is the CTM MOCAGE which was coupled to the weather forecast model ARPEGE by means of the PALM coupling software (Massart et al., 2005).

A coupled system (IFS-CTM) in which the IFS and a CTM are run in parallel was developed because of the envisaged high development cost to integrate and test complex chemical 


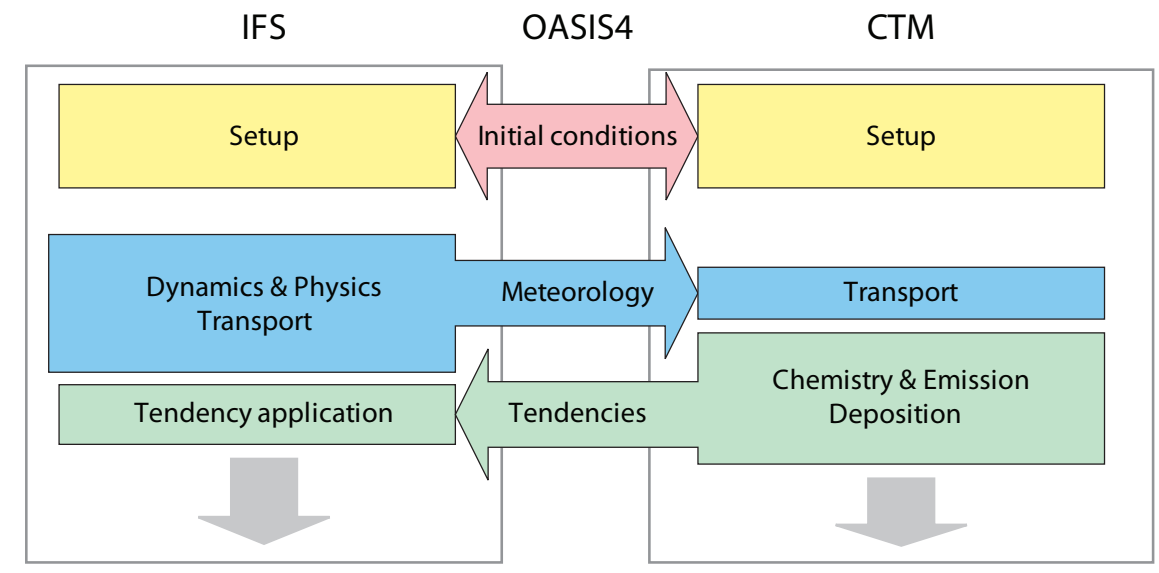

Fig. 1. Schematic of the data flow (setup and first time step) in the coupled system consisting of the IFS and one of the CTMs MOZART-3, TM5 or MOCAGE.

mechanisms as an integrated part of the IFS. The benefits from using ECMWF's operational data assimilation system and the associated infrastructure for observation processing would be difficult to keep if a new data assimilation system would be build around an existing CTM. Another advantage of the coupled system is the possibility to easily couple different CTMs to the IFS and therefore to be more flexible in the choice of the applied chemistry schemes. A coupled system of independent components can also better benefit from the ongoing development work of the stand-alone versions of the CTMs since the CTMs stay independent models. Finally, this approach allows for different grid resolutions in the IFS and CTM so that computing resources can be optimally used.

Although designed with the prospect of data assimilation, the coupled system can also be considered as an efficient way to provide meteorological parameters to a CTM at high temporal resolution without the need to access such fields from disk files. Furthermore, it is a research platform to (i) compare the physics parameterisations of the CTMs and that of the IFS, (ii) to inter-compare the chemical mechanisms of the CTMs by analyzing the tendency field due to chemistry (see Sect. 3.3), and (iii) to explore the impact of atmospheric composition on numerical weather prediction and its feedback to the tracer concentrations.

\subsection{Data exchange and experiment setup}

The coupled system is a three-dimensional two-way coupled system consisting of the IFS, one of the CTMs MOZART3, TM5 and MOCAGE and the coupler software OASIS4 (Redler et al., 2009). In the coupled system, the IFS simulates the advection, vertical turbulent tracer flux in the PBL (diffusion) and convection of selected chemical tracers (CO, $\mathrm{NO}_{\mathrm{x}}, \mathrm{HCHO}, \mathrm{SO}_{2}$ and $\mathrm{O}_{3}$ ) and applies tracer tendencies calculated by the coupled CTM to account for sink and source processes such as emission, chemical conversion and de- position. The prognostic tracer variables are also part of the control variables of the data assimilation mode in IFS. Figure 1 shows a schematic of the data flow in the coupled system. Every hour, the IFS provides meteorological fields to drive the CTMs and receives the CTM tendencies. Depending on the mode of operation (see below), concentration fields are exchanged from the IFS to the CTM or vice versa at the start of each coupled run in order to provide the initial conditions for the coupled run. The details of the application and formulation of the tendency terms are given in Sect. 2.3.

The choice of the exchanged meteorological fields depends on the requirements of the CTM. All CTMs receive fields of humidity, temperature, wind components, or divergence and vorticity in spectral representation, and sensible and latent heat flux. MOZART-3 and MOCAGE simulate their own hydrological cycle whereas TM5 also requires the IFS's precipitation and cloud fields, surface properties and convective mass fluxes.

The experiments with the coupled system are organized as a sequence of several 12-h runs in data assimilation mode or, in forecast mode, as runs up to four days starting every $24 \mathrm{~h}$ at 00:00 UTC. In data assimilation mode, the length of the coupled run is given by the length of the 4D-VAR assimilation window, which is normally $12 \mathrm{~h}$. A more detailed description of how the coupled system is used in data assimilation is given in Inness et al. (2009). In forecast mode, the meteorological fields in the IFS need to be initialized at least every $24 \mathrm{~h}$ with a meteorological analysis in order to avoid a drift from the observed state of the atmosphere.

At the start of each coupled run, the initial conditions of the coupled tracers in the IFS and the CTM are set to the same values: either the CTM fields replace the IFS tracer initial conditions fields (CTM-IC mode) or the IFS tracer fields replace the respective initial conditions of the CTM (IFS-IC mode). 
In CTM-IC mode, the CTM gets the whole set of initial conditions from the previous CTM run. In this configuration the concatenated CTM output of IFS-CTM is equivalent to the normal continuous CTM off-line run, except for the higher exchange frequency of meteorological fields.

In IFS-IC mode, CTM fields are used as IFS initial conditions only at the very first coupled run. In all subsequent runs, the IFS's coupled tracers are initialized from the previous IFS run and the respective CTMs fields are replaced by the IFS fields. The un-coupled CTM species are initialised from the previous CTM run as in CTM-IC mode. The IFS-IC mode is applied in data assimilation because the IFS tracer fields contain the assimilated information of the observations. The IFS-IC mode can also be applied to impose vertical tracer profiles simulated by the IFS on the CTM.

The change of certain CTM concentration fields in IFSIC mode may lead to chemical imbalances. However, at the start of an assimilation experiment, the adaptation towards the assimilated observation happens gradually over a couple of days so that the model is not confronted with completely different fields at a time. The assimilation runs with $\mathrm{O}_{3}$ and $\mathrm{CO}$ did not show pronounced imbalances or swift changes in chemically related species. Exploring the adaptation of the non-assimilated species has not been done yet.

\subsection{Formulation of tendency terms and their application in the IFS}

The exchange of concentration tendencies is a unique feature of the coupled system. The formulation of the tendency terms has to reflect (i) operator splitting and time-stepping in both the CTMs and the IFS, (ii) relative size and spatial structure of the tendency fields, and (iii) the computational cost of the exchange.

The CTMs use an operator-splitting approach in which advection, chemistry, emission injection, turbulent vertical diffusion and deposition are called in sequence, and the concentrations are updated directly within each operator subroutine. The IFS computes semi-lagrangian advection, turbulent vertical diffusion and convection of the tracers based on unperturbed concentration field values from the previous time step (Beljaars at al., 2004) and updates the concentration values with the accumulated tendency of all sink and source processes at the end of the time step.

The total CTM tendencies $T\left[\mathrm{~kg} \mathrm{~kg}^{-1} \mathrm{~s}^{-1}\right]$ are given by the sum of chemical loss $L_{C}$ and production $P_{C}$, production due to emission injection $P_{E}$ and loss $L_{D}$ due to deposition:

$T=P_{C}-L_{C}+P_{E}-L_{D}$

The injection of surface emissions is integrated in the MOZART-3 turbulent diffusion scheme, whereas TM5 and MOCAGE distribute the injected mass in a fixed ratio over selected layers near the surface and apply their turbulent diffusion operator after the injection. $P_{E}$ is therefore, at least for MOZART-3, a combination of the emission injection and the tendencies due to vertical turbulent diffusion. Since $P_{E}$ already contains the diffusion tendencies, its application in the IFS requires that the IFS turbulent diffusion scheme must not be applied again to the respective tracer fields. In order to also use the IFS diffusion scheme for the tracer transport within the coupled system, the effective net surface flux $\Phi_{E-D}$ from emissions and dry deposition is determined by calculating the total columns of the surface contribution of $P_{E}$ and the fraction of $L_{D}$ representing dry deposition. $\Phi_{E-D}$ is then presented as a surface flux to the IFS diffusion scheme and the components $P_{E}$ and $L_{D}$ are excluded from $T$ leaving $T_{\text {Air }}$.

Deposition $L_{D}$ and chemical loss $L_{C}$ are almost always proportional to the tracer concentration $x$. A relative formulation $L=l x$, i.e. a loss rate $l$, would have linked tendency and concentration values and would have helped to avoid negative concentrations after the application of the CTM tendencies in the IFS. However, it was decided against the relative formulation of tendencies because (i) it would have been be more difficult to distinguish chemical loss and production from the output arguments of the chemistry routines, which directly only provide the total change, and (ii) because a separate interpolation of production and loss tendencies, which often almost compensate each other, could have caused imbalances when the two fields are combined again in the IFS.

After consideration of the above arguments, it was decided to transfer and apply the process-specific tendencies of the CTM in one of the following two modes:

1. one 3-D tendency field $T$ containing all sources and sinks as well as diffusion (total-tendency mode),

2. one 3-D tendency field $T_{\text {Air }}$ and the effective $\Phi_{E-D}$ surface flux of emission and deposition (surface-flux mode).

\subsection{CTM and IFS specifications}

In the coupled system, the IFS runs with a T159 spectral resolution and the grid point space is represented by the reduced Gaussian grid (Hortal and Simmons, 1991), which has a grid box size of about $125 \mathrm{~km}$. The CTMs use a regular latitudelongitude grid of about $2^{\circ}-3^{\circ}$ grid box length. The coupler performs horizontal interpolations for which a bi-linear mode is applied. The IFS runs - for most parts of the globe - at a finer horizontal resolution than the CTMs because this improves (i) the quality of the meteorological forecasts and (ii) the acceptance of high resolution observations within data assimilation mechanism.

The IFS and all CTMs use the same vertical discretization of 60 hybrid sigma-pressure levels, reaching up to $0.1 \mathrm{hPa}$. The use of an identical vertical structure in the IFS and CTM avoids the need for vertical interpolation. The minimum coupling interval is $3600 \mathrm{~s}$ which is the largest acceptable time 
Table 1. Summary of CTM specifications.

\begin{tabular}{|c|c|c|c|}
\hline & MOZART-3 & TM5(KNMI-cy3-GEMS) & MOCAGE \\
\hline Horizontal resolution & $1.875^{\circ} \times 1.875^{\circ}$ & $2^{\circ} \times 3^{\circ}$ & $2^{\circ} \times 2^{\circ}$ \\
\hline Vertical resolution & 60 layers up to $0.1 \mathrm{hPa}$ & as MOZART-3 & as MOZART-3 \\
\hline Meteorological fields & Basic fields, heat fluxes & $\begin{array}{l}\text { as MOZART- } 3 \text { and precipitation, } \\
\text { clouds, convective mass fluxes } \\
\text { and surface properties }\end{array}$ & as MOZART-3 \\
\hline Advection & $\begin{array}{l}\text { Flux form semi-lagrangigain } \\
\text { (Lin and Rood, 1996) }\end{array}$ & $\begin{array}{l}\text { Slopes scheme } \\
\text { (Russel and Lerner, 1981) }\end{array}$ & $\begin{array}{l}\text { Semi-implicit, semi-lagrangian } \\
\text { (Williamson and Rasch, 1989) }\end{array}$ \\
\hline Convection scheme & $\begin{array}{l}\text { Hack (1994) for shallow and } \\
\text { mid-level convection, } \\
\text { Zhang and McFarlane (1995) } \\
\text { for deep convection }\end{array}$ & Tiedtke (1989) & $\begin{array}{l}\text { Bechtold et al. (2001), } \\
\text { completed by } \\
\text { Mari et al. (2000) }\end{array}$ \\
\hline Diffusion scheme & Holtslag and Boville (1993) & $\begin{array}{l}\text { Holtslag and Moeng (1991) } \\
\text { for near surface, Louis (1979) } \\
\text { for free troposphere }\end{array}$ & Louis (1979) \\
\hline Chemical mechanism & $\begin{array}{l}\text { JPL-03 and JPL-06 } \\
\text { (Sander et al., 2003, 2006) as } \\
\text { described in Kinnison et al. (2007), } \\
\mathrm{SO}_{\mathrm{X}} / \mathrm{NH}_{3} / \mathrm{NH}_{4} \text { mechanism from } \\
\text { MOZART-4 (Park et al., } 2009) \\
\text { (115 species, } 325 \text { reactions) }\end{array}$ & $\begin{array}{l}\text { CBM4 scheme as described in } \\
\text { Houweling et al. (1998) for } \\
\text { troposphere, stratospheric } \\
\mathrm{O}_{3} \text { climatology, Fortuin and } \\
\text { Kelder (1998) } \mathrm{HNO}_{3} \text { climatology } \\
\text { from UARS } \\
\text { (55 species, } 85 \text { reactions) }\end{array}$ & $\begin{array}{l}\text { REPROBUS } \\
\text { (Lefèvre et al., 1994) } \\
\text { scheme included in } \\
\text { the RACMOBUS scheme } \\
\text { (Carslaw et al., 1995) } \\
\text { for heterogeneous } \\
\text { stratospheric chemistry } \\
\text { (118 species and } 350 \text { reactions) }\end{array}$ \\
\hline Emissions & $\begin{array}{l}\text { RETRO (Schultz et al., 2009), } \\
\text { GFEDv2 (van der Wertft at al., 2006) }\end{array}$ & as MOZART-3 & as MOZART-3 \\
\hline
\end{tabular}

step for the IFS at a T159 resolution, and also the time step of some of the CTMs. An overview of the CTM resolution and parameterisations is given in Table 1.

\subsection{Computational performance of the coupled system}

A draw back of the coupled approach, in contrast to the online integration of chemistry modules in the IFS, is the reduced computational performance because of the longer CTM run-time and to a smaller extent also because the overhead introduced by the coupling. Whereas the IFS can be run highly efficient, the CTM run time on ECMWFs high performing facility could not be reduced to match that of the IFS. The run time of the CTM determined therefore the runtime of the coupled system and caused considerable latency in particular in data assimilation applications. In data assimilation mode the IFS has to use a larger amount of resources because of memory constraints. Table 2 lists the run time of the coupled system for a 24 -h forecast, for a 12 -h data assimilation cycle and the respective average turn over (simulation days per wall clock day). The turnover also reflects the time spend to archive the results and is highly depended on the supercomputer workload. Because of the long run-time
Table 2. Run-time in minutes and turnover (simulated days per day) of the stand-alone IFS and the coupled system IFS-MOZART, IFS-TM5 and IFS-MOCAGE in forecast (FC) and data assimilation (DA) mode. MOZART has been run on 64 CPUs, TM5 on 24 CPUs and MOCAGE on 12 CPUs. The IFS in FC mode has been run on 8 CPUs in FC mode and on 128 CPUs in DA mode.

\begin{tabular}{lcccc}
\hline Model & $\begin{array}{c}\text { Run time } \\
\text { 24-h FC }\end{array}$ & $\begin{array}{c}\text { Run time } \\
\text { 12-h DA }\end{array}$ & $\begin{array}{c}\text { Turn over } \\
\text { FC }\end{array}$ & $\begin{array}{c}\text { Turn over } \\
\text { DA }\end{array}$ \\
\hline IFS & $2 \mathrm{~min}$ & $20 \mathrm{~min}$ & 30 & 7 \\
IFS-MOZART & $9 \mathrm{~min}$ & $75 \mathrm{~min}$ & 12 & $3-4$ \\
IFS-TM5 & $15 \mathrm{~min}$ & $85 \mathrm{~min}$ & 10 & $3-4$ \\
IFS-MOCAGE & $130 \mathrm{~min}$ & - & - & - \\
\hline
\end{tabular}

MOCAGE was only applied for a couple of forecast runs. TM5s run has been improved to match that of MOZART-3 only in the last year of the projects. Therefore MOZART was used in the coupled near-real-time forecast runs and the re-analysis. 

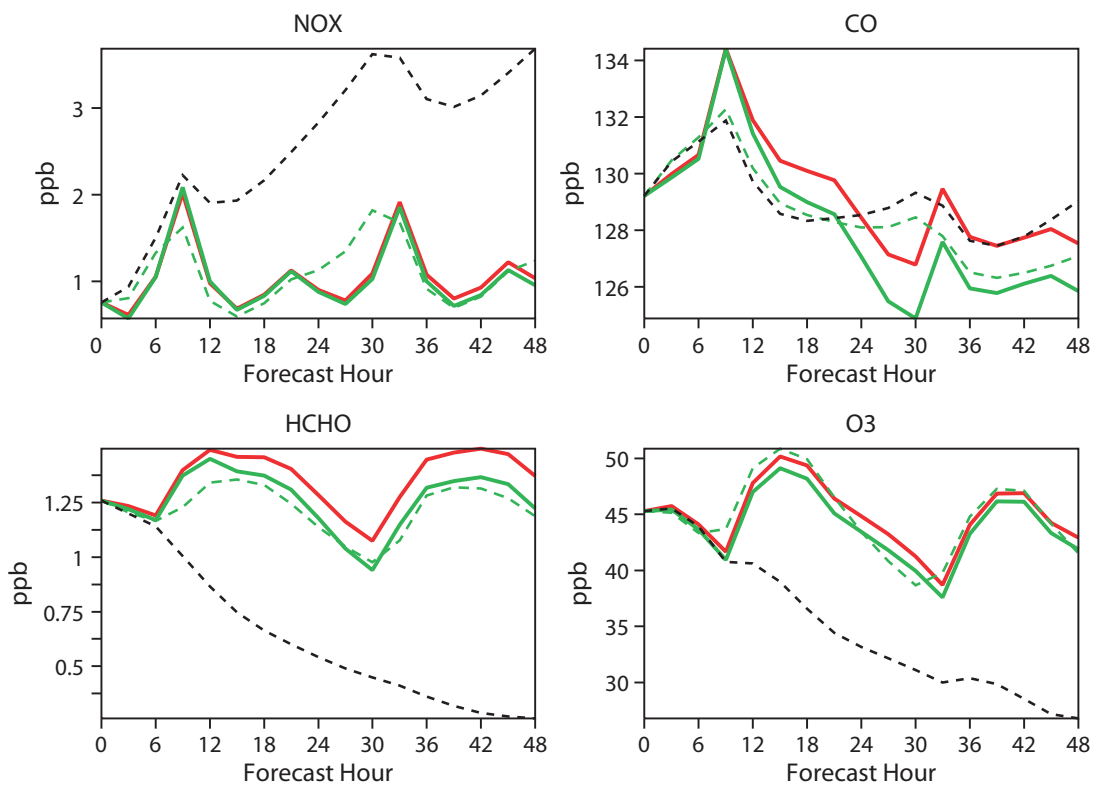

Fig. 2. Time series (forecast hour) of the area-averaged $\mathrm{NO}_{\mathrm{x}}, \mathrm{CO}, \mathrm{HCHO}$ and $\mathrm{O}_{3}$-concentrations over Europe at about $240 \mathrm{~m}$ simulated with the MOZART-3 (red), and simulated with the IFS applying MOZART-3 tendencies in total-tendency mode (green, solid), in surface-flux mode (green-dashed) and no application of tendencies (black, dotted). The coupled IFS tracer simulation (green) imitates that of the CTM MOZART-3 (green) in a satisfactory way.

\section{Scientific integrity of the coupled system}

\subsection{Comparing IFS-CTM concentrations with CTM concentrations}

The application of the CTM tendencies to IFS tracers is an approximation because the underlying CTM concentrations could be dislocated from the concentration patterns in the IFS. This dislocation may occur because of (i) the horizontal interpolation from the CTM to the IFS grid and (ii) the differences between the CTM and the IFS transport. In the case of the coupled system, both the IFS and the CTM simulate atmospheric transport processes. Different advection schemes or spatial and temporal resolutions may lead to different concentration fields in the IFS and the CTM.

The most severe consequence of the dislocated tendencies would be negative concentration values in the IFS because of unbalanced loss processes. The severity of the impact of the dislocation depends on the sensitivity of the sink and sources on the concentration itself, i.e. the speed of the chemical conversion and the intensity of the deposition.

In order to minimise the dislocation, the CTM and the IFS concentration fields have to be made as similar as possible by not letting the transport schemes develop different concentration patterns and by periodically aligning the concentration fields in the IFS to the ones in the CTM or vice versa. This aligning is ensured by letting the coupled tracers in the IFS and the CTM start from the same initial conditions (see Sect. 2.2) either in CTM-IC mode or IFS-IC mode.
The integrity of the coupled system depends on whether the application of external tendency fields accounting for processes not included in the IFS (chemistry, emission and deposition) gives reasonable results for the forecast length. The objective is that the IFS is able to imitate the CTM concentration changes. Therefore, the development of the differences between the IFS tracer fields and their counterpart in the CTM in coupled runs starting from the same MOZART-3 initial conditions was studied. The resemblance of the fields was carefully checked and no unreasonable features in the IFS fields were discovered. The only obvious problem occurred during an earlier attempt to couple $\mathrm{NO}_{2}$ rather than $\mathrm{NO}_{\mathrm{x}}$. The stratospheric NO-NO 2 conversion at sunrise and sunset, which moves around the globe, could not satisfactorily be captured by the coupled system with an exchange frequency of one hour because stripe-shaped minima occurred in the IFS $\mathrm{NO}_{2}$-fields at the previous positions of the terminator. To avoid this problem, it was decided to use $\mathrm{NO}_{\mathrm{x}}$ as a coupled species, which did not show the stripe-like undulation as a consequence of the constantly progressing terminator seen in the $\mathrm{NO}_{2}$-fields.

To demonstrate the accuracy of the tendencies application method, Fig. 2 shows exemplary time series of spatially averaged $\mathrm{O}_{3}, \mathrm{CO}, \mathrm{HCHO}$ and $\mathrm{NO}_{\mathrm{x}}$ concentrations from the coupled system IFS-MOZART for model layer 55 (about $240 \mathrm{~m}$ above the surface) over Europe. Shown are the two modes of the tendency application (total-tendency and surface-flux mode, see Sect. 2.2) as well as no tendency application. When 
no source and sink tendencies were applied the averaged IFS tracer quickly diverged from the CTM reference showing the general need for the tendency application also in a time scale of a few hours. When total tendencies were applied, the IFS could imitate the CTM up to a forecast length of $48 \mathrm{~h}$. The differences were larger, in particular for primary species, when the IFS vertical diffusion scheme injected the effective surface flux $\Phi_{E-D}$, indicating a stronger diffusion in the IFS.

To gain a more detailed overview of the ability of the IFS tracers to follow the CTM concentration fields, the relative difference between IFS and CTM fields were calculated for each model grid point and forecast hour in both modes of the tendency application (see Sect. 2.2). The relative differences were obtained by normalizing with the range, i.e. the difference between maximum and minimum value of the CTM concentration in the respective atmospheric region because it prevents the normalisation with concentration values close to zero. Table 3 contains the percentage of grid points with relative differences lower than $1 \%, 10 \%$, and $100 \%$, discriminating between the PBL, the free troposphere and the stratosphere for the "surface-flux" mode. In the PBL the differences in "total-tendency" mode were smaller than the differences in "surface-flux" because the CTMs diffusion tendencies are directly used in the IFS. The differences were of the same size in the rest of the atmosphere.

The discrepancy between the IFS and the CTM coupled tracers developed quickly after the first data exchange and increased from there onwards much more slowly with increasing forecast length. But even after $24 \mathrm{~h}$ the differences were less than $10 \%$ at more than $97 \%$ of the grid points for every species. When studying the more strict error limit of discrepancies less than $1 \%$, only about $30 \%$ of the $\mathrm{O}_{3}$ in the PBL could be simulated by the IFS with this accuracy, whereas for the other species $80-90 \%$ of the grid points satisfied this criterion. The largest absolute differences occurred in the PBL, indicating the high variability in this part of the atmosphere because of emissions injection, diffusion and active chemistry.

\subsection{Comparing IFS-CTM errors with CTM errors}

This section deals with the question whether the identified small differences (see Table 3) mean that either the CTM or IFS-CTM concentration fields have smaller errors against observations. The comparison has been carried out with a few but globally distributed surface observation because the IFS and CTM surface concentrations are most likely to differ in the PBL.

The concentrations fields in IFS and in MOZART as part of IFS-MOZART's pre-operational forecast were compared against surface observation from the Global Atmosphere Watch network at the stations Hohenpeissenberg (HPB, Germany), Monte Cimone (MCI, Italy), Izana (IZO, Tenerife), Santa Cruz (STC, Tenerife), Tamanrasset-Assekrem (TAM,
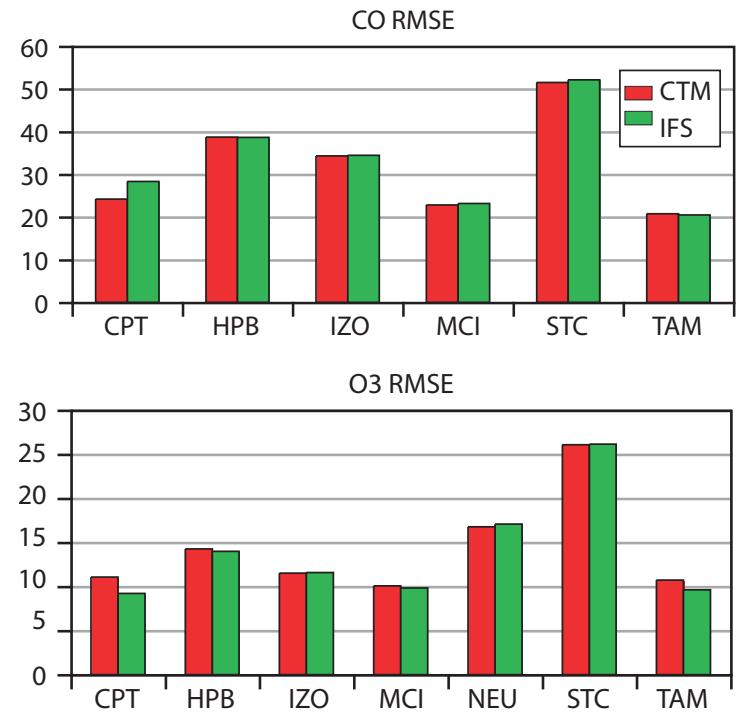

Fig. 3. RMSE for $\mathrm{CO}$ (top) and $\mathrm{O}_{3}$ (bottom) for the period September-November 2008 calculated from tracer fields of the IFS in the coupled system (IFS-MOZART) and from direct MOZART3 output for the stations Hohenpeissenberg (HPB), Monte Cimone (MCI), Izana (IZO), Santa Cruz (STC), Tamanrasset-Assekrem (TAM), Cape Point (CPT) and Neumayer station (NEU, no CO data).

Algeria), Cape Point (CPT, South Africa) and Neumayer (NEU, Antartica) for the period September-November 2008.

The RMSE of three-hourly data (see Fig. 3) was of very similar value for most of the stations, indicating no significant difference in the performance of the coupled system compared to the CTM stand-alone run. The largest differences occurred at the station CPT where $\mathrm{O}_{3}$ was better simulated by the IFS in the coupled system and $\mathrm{CO}$ better by the stand-alone CTM. Figures 4 and 5 show time series of the observation and the simulation of the coupled system and the MOZART-3 direct output at CPT. There was a minimal offset, which was small compared to the bias against the observations, between the coupled system and the direct CTM output, which caused a higher or lower RMSE for CO and $\mathrm{O}_{3}$, respectively. The height of the peaks was higher in the coupled model output which seems to better match the observations. It was inferred that the differences between the IFS and CTM fields were mainly caused by the different horizontal grid partitioning in the IFS and the CTM, which attributes a different amount of emission in the grid box where the observation is located.

Given the overall uncertainty of the concentration values and the anticipated changes due to data assimilation, it was concluded that IFS concentration fields were scientifically sound since they resembled the CTM fields to a high degree.

The coupled system IFS-MOZART has been thoroughly evaluated against observations elsewhere. Ordóñez et al. (2009) present the evaluation of the coupled system in the 
Table 3. Fraction of grid points (in \%) with relative differences between CTM and IFS value below 1\%, 10\%, and 100\% at different forecast lengths for the PBL, the free troposphere and the stratosphere. The run applied the "surface fluxes" mode. The differences have been normalised with the concentration range in the respective area and forecast step.

\begin{tabular}{|c|c|c|c|c|c|c|c|c|c|c|}
\hline \multirow[t]{2}{*}{ Species } & \multirow{2}{*}{$\begin{array}{l}\text { Forecast } \\
\text { length }\end{array}$} & \multicolumn{3}{|c|}{ PBL } & \multicolumn{3}{|c|}{ Troposphere } & \multicolumn{3}{|c|}{ Stratosphere } \\
\hline & & $<1 \%$ & $<10 \%$ & $<100 \%$ & $<1 \%$ & $<10 \%$ & $<100 \%$ & $<1 \%$ & $<10 \%$ & $<100 \%$ \\
\hline $\mathrm{NO}_{\mathrm{x}}$ & 3 & 92.7 & 99.4 & 100.0 & 90.9 & 99.4 & 100.0 & 57.0 & 99.8 & 100.0 \\
\hline $\mathrm{NO}_{\mathrm{x}}$ & 12 & 89.5 & 99.3 & 100.0 & 85.6 & 99.0 & 100.0 & 50.1 & 99.6 & 100.0 \\
\hline $\mathrm{NO}_{\mathrm{x}}$ & 24 & 84.3 & 98.4 & 100.0 & 76.2 & 96.7 & 99.9 & 47.2 & 99.5 & 100.0 \\
\hline $\mathrm{NO}_{\mathrm{x}}$ & 36 & 87.1 & 98.8 & 100.0 & 76.2 & 97.1 & 100.0 & 44.5 & 99.2 & 100.0 \\
\hline $\mathrm{NO}_{\mathrm{x}}$ & 48 & 76.4 & 95.5 & 99.8 & 73.1 & 95.7 & 99.9 & 43.3 & 99.1 & 100.0 \\
\hline $\mathrm{CO}$ & 3 & 96.6 & 99.9 & 100.0 & 94.2 & 99.9 & 100.0 & 84.1 & 99.9 & 100.0 \\
\hline $\mathrm{CO}$ & 12 & 93.8 & 99.8 & 100.0 & 77.7 & 99.2 & 100.0 & 70.9 & 99.6 & 100.0 \\
\hline $\mathrm{CO}$ & 24 & 91.0 & 99.6 & 100.0 & 66.8 & 98.5 & 100.0 & 66.1 & 99.4 & 100.0 \\
\hline $\mathrm{CO}$ & 36 & 90.7 & 99.7 & 100.0 & 62.8 & 98.0 & 100.0 & 59.9 & 99.0 & 100.0 \\
\hline $\mathrm{CO}$ & 48 & 88.2 & 99.6 & 100.0 & 60.0 & 97.7 & 100.0 & 57.7 & 98.8 & 100.0 \\
\hline $\mathrm{HCHO}$ & 3 & 93.5 & 99.9 & 100.0 & 88.9 & 99.3 & 100.0 & 57.9 & 96.3 & 99.9 \\
\hline $\mathrm{HCHO}$ & 12 & 86.1 & 99.5 & 100.0 & 73.9 & 96.6 & 100.0 & 50.4 & 94.6 & 99.6 \\
\hline $\mathrm{HCHO}$ & 24 & 81.3 & 99.2 & 100.0 & 62.7 & 92.9 & 100.0 & 49.4 & 94.2 & 99.7 \\
\hline $\mathrm{HCHO}$ & 36 & 81.6 & 99.2 & 100.0 & 64.2 & 93.7 & 100.0 & 45.8 & 93.1 & 99.5 \\
\hline $\mathrm{HCHO}$ & 48 & 78.3 & 99.1 & 100.0 & 54.4 & 90.3 & 100.0 & 45.1 & 93.7 & 99.6 \\
\hline $\mathrm{O}_{3}$ & 3 & 69.5 & 99.4 & 100.0 & 81.0 & 99.8 & 100.0 & 80.2 & 100.0 & 100.0 \\
\hline $\mathrm{O}_{3}$ & 12 & 38.4 & 97.9 & 100.0 & 51.6 & 97.9 & 100.0 & 67.0 & 99.9 & 100.0 \\
\hline $\mathrm{O}_{3}$ & 24 & 30.6 & 97.1 & 100.0 & 40.4 & 96.6 & 100.0 & 60.4 & 99.8 & 100.0 \\
\hline $\mathrm{O}_{3}$ & 36 & 24.4 & 95.7 & 100.0 & 35.2 & 95.4 & 100.0 & 55.2 & 99.7 & 100.0 \\
\hline $\mathrm{O}_{3}$ & 48 & 24.7 & 96.7 & 100.0 & 32.0 & 94.5 & 100.0 & 51.9 & 99.5 & 100.0 \\
\hline $\mathrm{SO}_{2}$ & 3 & 97.3 & 99.9 & 100.0 & 96.4 & 99.7 & 100.0 & 97.4 & 99.7 & 100.0 \\
\hline $\mathrm{SO}_{2}$ & 12 & 95.5 & 99.7 & 100.0 & 91.0 & 98.8 & 100.0 & 92.0 & 98.8 & 100.0 \\
\hline $\mathrm{SO}_{2}$ & 24 & 93.4 & 99.4 & 100.0 & 88.6 & 98.3 & 99.9 & 88.6 & 98.4 & 99.9 \\
\hline $\mathrm{SO}_{2}$ & 36 & 93.8 & 99.5 & 100.0 & 83.1 & 96.8 & 99.9 & 83.1 & 96.8 & 99.9 \\
\hline $\mathrm{SO}_{2}$ & 48 & 92.2 & 99.2 & 100.0 & 82.1 & 96.6 & 99.9 & 83.0 & 96.6 & 100.0 \\
\hline
\end{tabular}

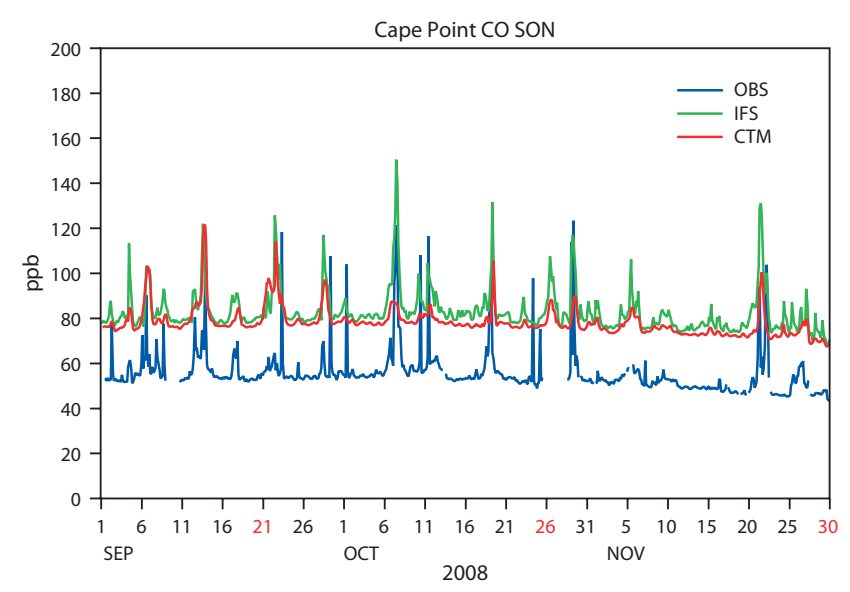

Fig. 4. Time series of CO modelled by the IFS in the coupled system (IFS, green) and by the CTM MOZART-3 (MOZ, red) and observations (OBS, blue) for the GAW station Cape Point, which showed the larges differences in RMSE between IFS and CTM for the period September-November 2008.

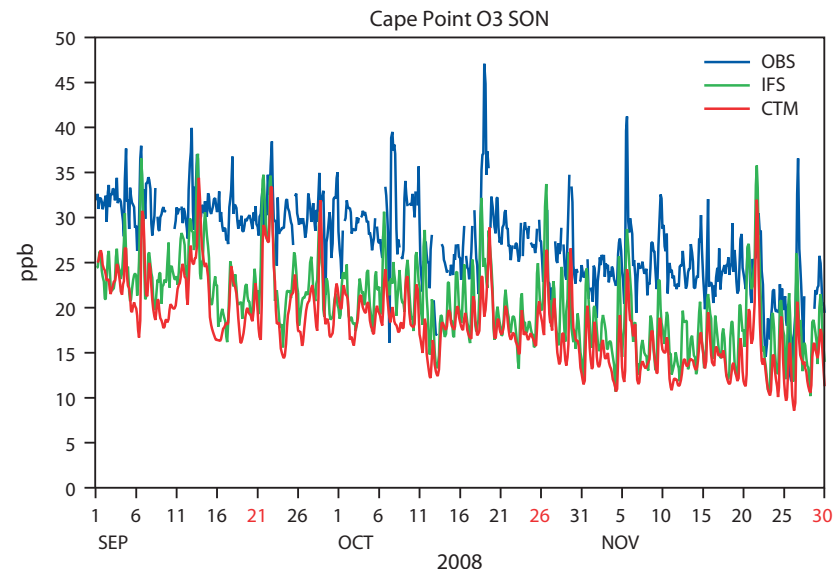

Fig. 5. Time series of $\mathrm{O}_{3}$ modelled by the coupled system (IFS, green) and by the CTM (MOZ, red) and observations (OBS, blue) for the GAW station Cape Point, which showed the larges differences in RMSE between IFS and CTM for the period SeptemberNovember 2008. 

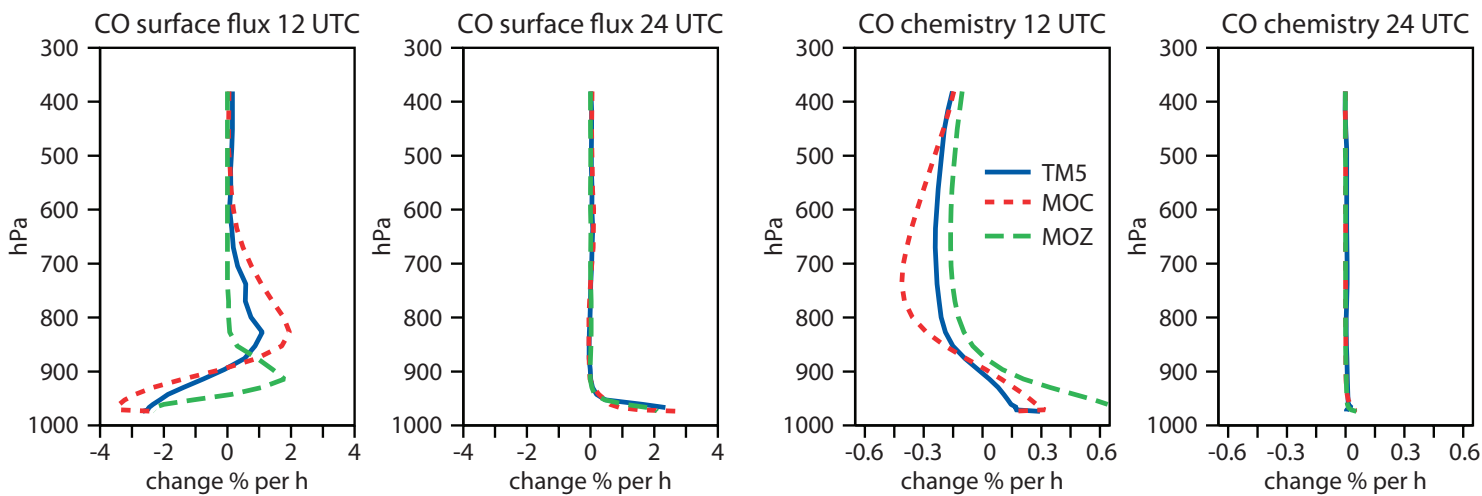

Fig. 6. Profile of the averaged changes per hour in percent of CO over Europe due to surface fluxes (emissions and dry deposition) vertically distributed by the PBL scheme (left two panels) and due to chemistry (right two panels) from TM5, MOZART-3 (MOZ) and MOCAGE (MOC) at 12:00 and 24:00 UTC.

troposphere during the 2003 European heat wave. A paper in preparation will aim at the evaluation of forecast and assimilation of the Antarctic ozone hole in 2008. Comparison against satellite observations of $\mathrm{O}_{3}, \mathrm{CO}, \mathrm{NO}_{\mathrm{x}}, \mathrm{HCHO}$ and $\mathrm{SO}_{2}$ can be found in Innes et al. (2009). The "GEMS GRG Comprehensive Validation Report project report" (Cammas et al., 2009) contains more evaluation studies of the CTMs and the coupled system. Further, the performance of the coupled stand-alone CTMs has already been published in the papers cited in Sect. 1.

\subsection{Model diagnostics based on the tendency terms}

Studying the source and sink tendencies from the emission injection and chemical conversion may help to gain more insight into the CTMs. In a case study, the tendency terms from the different source and sink processes were analysed with emphasis on the troposphere over all 287 land points in Central Europe (42N/-10W-55N/10E) for a ten day period in June 2004.

Vertical profiles of the area-averaged concentration changes from each CTM were calculated for day (12:00 UTC) and night conditions (00:00 UTC) and, for display, normalised with the area-averaged concentrations. The "chemistry" profile includes the net chemical conversion and the negligible contributions from wet deposition and air-borne emissions ( $T_{\text {Air }}$, see Sect. 2.3). The "emission" profile comprises the three-dimensional tendencies due to vertical distribution of the surface fluxes (emissions and dry deposition) by the turbulent diffusion scheme. Its shape many reflects the difference in the PBL parameterizations of the CTMs. The total column of the "emission" profile was used to calculate the net surface flux $\Phi_{E-D}$ in "surface-flux" mode. The sum the "emissions" and "chemistry" profile is equal to $T$ in total-tendency mode.
The $\mathrm{CO}$ tendencies for emission injection and diffusion (Fig. 6, left) during the day showed that diffusion, despite $\mathrm{CO}$ emissions, leads to a concentration decrease close to the surface and an accumulation in the upper part of the boundary layer. The accumulation zone in MOZART-3 was largely confined to $900 \mathrm{hPa}$ whereas the vertical transport in TM5 and MOCAGE reached higher levels, indicating more pronounced diffusion and convection. The stable conditions during the night caused increasing $\mathrm{CO}$ concentration values only in the lowest two to three model levels in all CTMs. The chemical conversion of CO (Fig. 6, right) is linked to daytime photochemistry, which explains the absence of concentration changes during the night for all models. Emissions of CO caused an increase of up to $3 \%$ and its chemical depletion was up to $1 \%$ of the concentration value per hour (Fig. 6). The relative $\mathrm{CO}$ concentration changes due to chemistry were smaller $(\sim 1 \%)$ than the changes due to emissions and diffusion $(\sim 3 \%)$. However, chemical CO loss occurred throughout the vertical column of the troposphere. All models simulated $\mathrm{CO}$ depletion due to oxidation with $\mathrm{OH}$ in the free troposphere. In spite of similar formulations of the chemical rate constant for $\mathrm{CO}$ oxidation, the relative chemical tendency of $\mathrm{CO}$ among the three CTMs differs by more than a factor of two. MOCAGE showed the strongest chemical loss both in relative and absolute terms. A comparison of the $\mathrm{OH}$ concentrations of the three CTMs confirmed that MOCAGE's average $\mathrm{OH}$ concentrations were higher by about 0.05 ppt than TM5 and by 0.07 ppt than MOZART-3. The CTMs simulated a net chemical production of $\mathrm{CO}$ due to oxidation of volatile organic compounds in the PBL, which was smallest in TM5 and largest in MOZART-3.

$\mathrm{NO}_{\mathrm{x}}$ was the most variable species with average changes per hour of up to $30 \%$ of the concentration value for both chemistry and emission injection. The vertical profile of the surface flux related tendencies for $\mathrm{NO}_{\mathrm{x}}$ resembled that of $\mathrm{CO}$ 

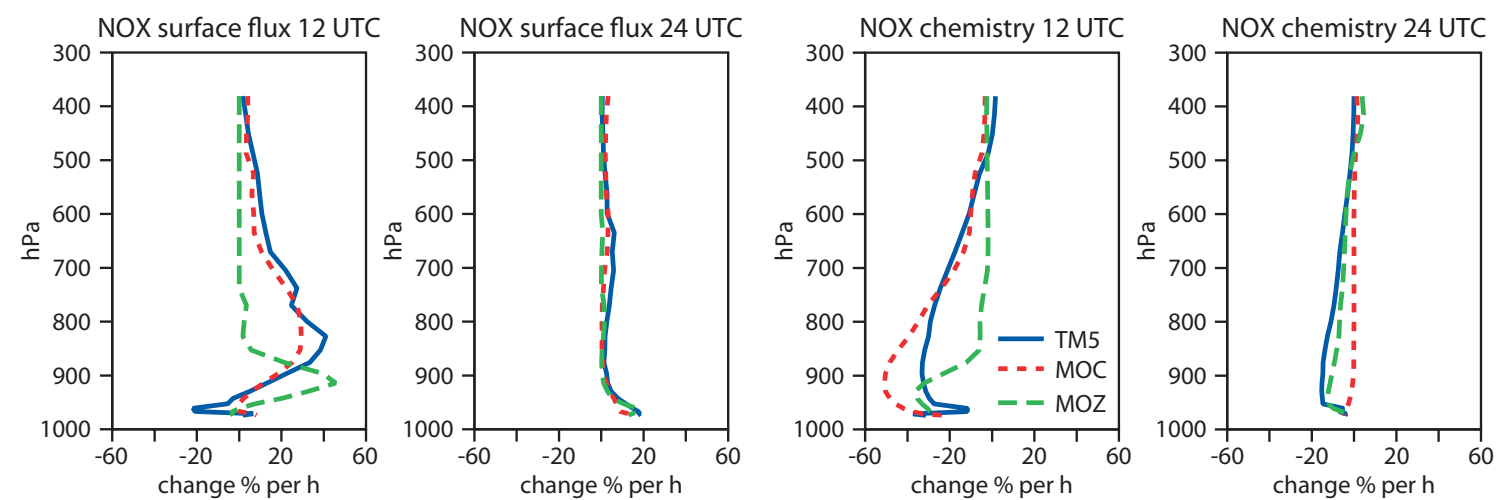

Fig. 7. Profile of the averaged changes per hour in percent of $\mathrm{NO}_{\mathrm{x}}$ over Europe due to surface fluxes (emissions and dry deposition) vertically distributed by the PBL scheme (left two panels) and due to chemistry (right two panels) from TM5, MOZART-3 (MOZ) and MOCAGE (MOC) at 12:00 and 24:00 UTC.
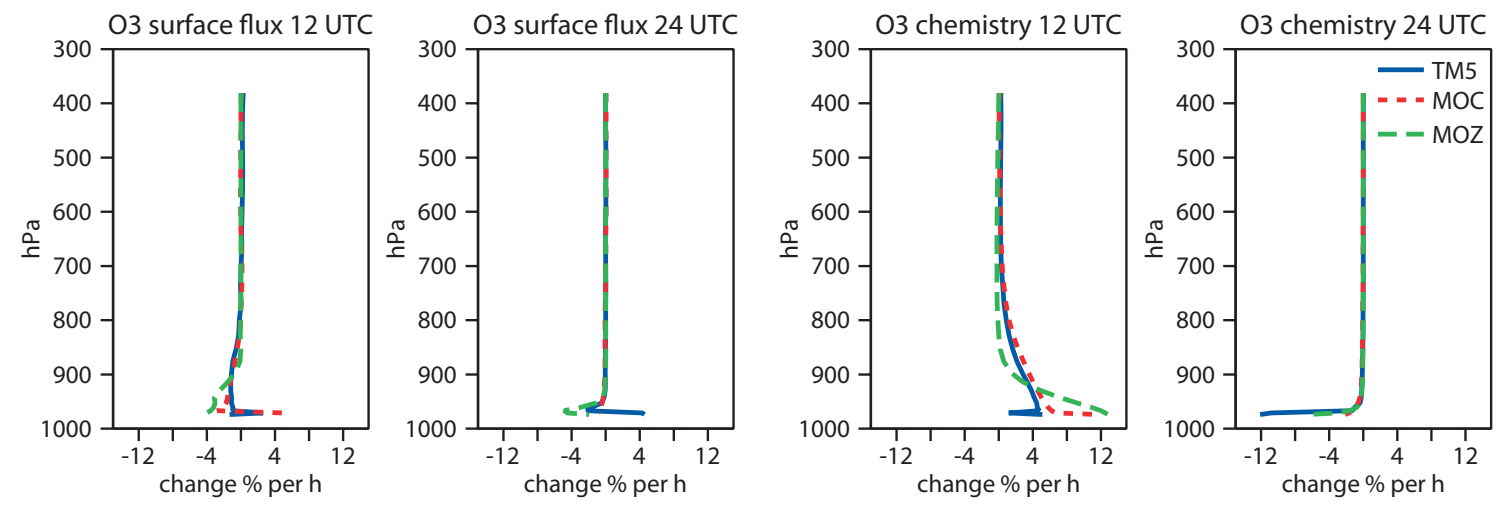

Fig. 8. Profile of the averaged changes per hour in percent of $\mathrm{O}_{3}$ over Europe due to surface fluxes (dry deposition) vertically distributed by the PBL scheme (left two panels) and due to chemistry (right two panels) from TM5, MOZART-3 (MOZ) and MOCAGE (MOC) at 12:00 and 24:00 UTC.

although the relative changes were about ten times larger (Fig. 7, left). The mixing of the emissions during the day was again limited to a shallower layer in MOZART-3 compared to the other CTMs. The chemistry (Fig. 7, right) caused a loss of $\mathrm{NO}_{\mathrm{x}}$ in the lower troposphere of up to $40 \%$ per hour during the day because of conversion into $\mathrm{HNO}_{3}$ and PAN. Again MOCAGE simulated the strongest tropospheric $\mathrm{NO}_{\mathrm{x}}$ depletion during the day because of the higher $\mathrm{OH}$ concentrations. During the night, only TM5 and MOZART- 3 computed tropospheric $\mathrm{NO}_{\mathrm{x}}$ loss, in the range of $10 \%$, probably due to the heterogeneous $\mathrm{N}_{2} \mathrm{O}_{5}$ uptake on clouds and aerosols, which is not included in MOCAGE.

The maximum relative $\mathrm{O}_{3}$ changes were due to chemistry and reached up to $5 \%$ in the PBL (Fig. 8). The $\mathrm{O}_{3}$ surface flux (Fig. 8, left) is caused by dry deposition at the surface. Compared to this large loss, the averaged diffusion did not contribute substantially to a systematic vertical concentration change in any of the CTMs. During the day, $\mathrm{O}_{3}$ production occurred in the PBL of all CTMs, and $\mathrm{O}_{3}$ loss occurred in the lowest layer during the night because of titration with
$\mathrm{NO}_{\mathrm{x}}$, which was concentrated there. The comparatively low $\mathrm{O}_{3}$ loss can be attributed to the fact that most of the titration took place before midnight. Only TM5 simulated reduced $\mathrm{O}_{3}$ production in the lowest layer during the day, which was probably related to the high $\mathrm{NO}_{\mathrm{x}}$ increase there.

\section{Summary and conclusions}

The design and the validation of a coupled system which links the ECMWF's Integrated Forecast and data assimilation System (IFS) to each of the three global CTMs, MOZART-3, TM5 and MOCAGE, are presented in this paper. The purpose of the coupled system is to enable the IFS to simulate global reactive gases in order to provide forecasts and analyses of atmospheric composition without directly integrating complex chemistry schemes, emission injection and deposition into the IFS. The coupled system is an alternative approach to the on-line integration of chemistryschemes in meteorological models. The main motivation for 
developing the coupled system was the ease with which different chemical schemes could be tested, and the reduced development effort. The coupled system IFS-CTM can directly utilise the IFS 4D-VAR algorithm to assimilate observations of atmospheric trace gases such as $\mathrm{CO}$, tropospheric and stratospheric $\mathrm{O}_{3}, \mathrm{SO}_{2}, \mathrm{NO}_{\mathrm{x}}$ and $\mathrm{HCHO}$. This paper focuses on the ability of the coupled IFS to simulate sound concentration fields by comparing them to the concentration fields of the coupled CTM, which they should closely resemble.

In the coupled system, the CTM is driven by the meteorological data received from the IFS. The special characteristic of the coupled system is that the IFS receives either threedimensional tendencies accounting for all source and sink processes or three-dimensional tendencies due to chemistry and net surface fluxes accounting for emission and dry deposition. The respective tendencies and fluxes are applied to the IFS concentration fields, whose transport has is modelled by the IFS.

To prove the validity of the coupled approach, the chemical tracers in the coupled system IFS-MOZART were compared with concentration fields from MOZART-3. Only small differences were found for a period of about $48 \mathrm{~h}$. The largest differences occurred in the PBL. A comparison with observations from the GAW network showed that these small differences lead to sometimes slightly bigger and sometimes smaller errors with respect to observations.

The exchange of tendencies describing emission injection and deposition as well as chemical conversion is a special feature of the coupled system. The tendencies were used for a process-oriented inter-comparison of the three CTMs, MOZART-3, TM5 and MOCAGE, over Europe in June 2004. Averaged profiles for day and night conditions showing the impact of the surface fluxes (emissions and dry deposition) vertically distributed by the turbulent diffusion scheme were compared with profiles showing the impact of the chemical conversion. Despite the surface emission, diffusion caused a net loss close to the surface and an accumulation in the upper part of the PBL in all CTMs during the day. The day-time vertical mixing was shallowest in MOZART-3. The chemical loss of $\mathrm{CO}$ and $\mathrm{NO}_{\mathrm{x}}$ linked to the reaction with the hydroxyl radical was highest in MOCAGE. In contrast MOCAGE's night time $\mathrm{NO}_{\mathrm{x}}$ depletion was much lower than that of the other two CTMs, with TM5 simulating the largest chemical $\mathrm{NO}_{\mathrm{x}}$ loss. MOCAGE's dry deposition of $\mathrm{O}_{3}$ was confined to the lowest model layer and was stronger than in the other CTMs.

The coupled system IFS- MOZART-3 has been applied to provide forecasts of atmospheric composition since May 2007. The results of the $\mathrm{O}_{3}$ and $\mathrm{CO}$ forecast are published daily at the GEMS web-site http://gems.ecmwf.int/d/ products/grg/realtime/. Besides providing a global picture of atmospheric composition, the results of the NRT forecast are used as boundary conditions for European regional air quality models run daily within the GEMS project.
In summary, the IFS tracer fields of the coupled system compared well with the corresponding CTM fields and with $\mathrm{CO}$ and $\mathrm{O}_{3}$ observations. It can be concluded that the coupled system is a flexible and scientifically sound instrument for the forecast of atmospheric composition. These are important pre-requisites for its use in the assimilation of satellite observation of reactive trace gases, which has already been demonstrated by Inness et al. (2009). The coupled system further provides valuable insight for process-oriented model evaluation because of its direct access to contribution of source and sink processes.

Acknowledgements. We would like to thank the two anonymous reviewers for their insightful comments during the review process. We thank the operators of the Global Atmosphere Watch stations Hohenpeißenberg, Monte Cimone, Izana, Santa Cruz, TamanrassetAssekrem, Cape Point and Neumeyer station for the provision of their observational data. We would like to acknowledge Rene Redler's and Sophie Valcke's support during the implementation of the OASIS4 coupler software, and Arjo Segers for including the coupling interface in TM5. The work has been carried out in the GEMS project, which is funded by the European Commission under the EU Sixth Research Framework Programme, contract number SIP4-CT-2004-516099. Finally, we would like to acknowledge Tony Hollingsworth who sadly passed away in summer 2007 for his enthusiastic support and for being the first to sketch out the design of the coupled system.

Edited by: P. Jöckel

\section{References}

Bechtold, P., Bazile, E., Guichard, F., Mascart, P., and Richard, E.: A mass flux convection scheme for regional and global models, Q. J. Roy. Meteor. Soc., 127, 869-886, 2001.

Beljaars, A., Bechtold, P., Kohler, M., Morcrette, J.-J., Tompkins, A., Viterbo, P., and Wedi, N.: The numerics of physical parameterization, Seminar on Recent developments in numerical methods for atmospheric and ocean modelling, http://www.ecmwf.int/ publications/library/do/references/, 6-10 September 2004.

Bousserez, N., Attié, J.-L., Peuch, V.-H., Michou, M., and Pfister, G.: Evaluation of the MOCAGE chemistry and transport model during the ICARTT/ITOP experiment, J. Geophys. Res., 112, D10S42, doi:10.1029/2006JD007595, 2007.

Cammas J.-P., Gilles, A., Chabrillat, S., Daerden, F., Elguindi, N., Flemming, J., Flentje, H., Granier, C., Huijnen, V., Inness, A., Jones, L., Katragkou, E., Khokhar, F., Kins, L., Law, K., Lefever, K., Leitao, J., Melas, D., Moinat, P., Ordonez, C., Peuch, V.H., Reich, G., Schultz, M., Stein, O., Thouret, V., Werner, T., and Zerefos, C.: GEMS GRG Comprehensive Validation Report, Toulouse, available as project report at: http://gems.ecmwf.int, 2009.

Carslaw, K. S., Luo, B., Peter, T., and Clegg, S. L.: Vapour pressures of $\mathrm{H}_{2} \mathrm{SO}_{4} / \mathrm{HNO}_{3} / \mathrm{HBr} / \mathrm{H}_{2} \mathrm{O}$ solutions to low stratospheric temperatures, Geophys. Res. Lett., 22, 247-250, 1995.

Engelen, R. J., Serrar, S., and Chevallier, F.: Four-dimensional data assimilation of atmospheric $\mathrm{CO}_{2}$ using AIRS observations, J. Geophys. Res., 114, D03303, doi:10.1029/2008JD010739, 2009. 
Fortuin, J. P. F. and Kelder, H.: An ozone climatology based on ozonesonde and satellite measurements, J. Geophys. Res., 103, 31709-31734, 1998.

Ford, R. W. and Riley, G. D: FLUME coupling review, UK met-office, available at: http://www.metoffice.gov.uk/research/ interproj/flume/pdf/d3_r8.pdf, 2002.

Grell, G. A., Peckham, S. E., Schmitz, R., McKeen, S. A., Frost, G. J., Skamarock, W., and Eder, B.: Fully coupled online chemistry within the WRF model, Atmos. Environ., 39(37), 6957-6975, 2005.

Hack, J. J.: Parameterization of moist convection in the NCAR community climate model (CCM2), J. Geophys. Res., 99, 55515568, 1994.

Hollingsworth, A., Engelen, R. J., Textor, C., Benedetti, A., Boucher, O., Chevallier, F., Dethof, A., Elbern, H., Eskes, H., Flemming, J., Granier, C., Kaiser, J. W., Morcrette, J.-J., Rayner, P., Peuch, V. H., Rouil, L., Schultz, M. G., Simmons, A. J., and The GEMS Consortium: Toward a Monitoring and Forecasting System For Atmospheric Composition: The GEMS Project, B. Am. Meteorol. Soc., 89, 1147-1164, 2008.

Holtslag, A. A. and. Moeng, C.-H: Eddy diffusivity and countergradient transport in the convective atmospheric boundary layer, J. Atmos. Sci., 48, 1690-1698, 1991.

Holtslag, A. A. and Boville, B.: Local versus nonlocal boundarylayer diffusion in a global climate model, J. Climate, 6, 18251842, 1993.

Hortal, M. and Simmons, A. J.: Use of reduced Gaussian grids in spectral models, Mon. Weather Rev., 119, 1057,-1074, 1991.

Houweling, S., Dentener, F., and Lelieveld, J.: The impact of nonmethane hydrocarbon compounds on tropospheric photochemistry, J. Geophys. Res., 103(D9), 10673-10696, 1998.

Inness, A., Flemming, J., Suttie, M., and Jones, L.: GEMS data assimilation system for chemically reactive gases, European Centre for Medium-Range Weather Forecasts (ECMWF), Technical Memoradum No. 587, 2009.

Josse, B., Simon, P., and Peuch, V.-H.: Rn-222 global simulations with the multiscale CTM MOCAGE, Tellus B, 56, 339-356, 2004.

Kaminski, J. W., Neary, L., Struzewska, J., McConnell, J. C., Lupu, A., Jarosz, J., Toyota, K., Gong, S. L., Côté, J., Liu, X., Chance, K., and Richter, A.: GEM-AQ, an on-line global multiscale chemical weather modelling system: model description and evaluation of gas phase chemistry processes, Atmos. Chem. Phys., 8, 3255-3281, 2008,

http://www.atmos-chem-phys.net/8/3255/2008/.

Kinnison, D. E., Brasseur, G. P., Walters, S., Garcia, R. R., Marsh, D. R., Sassi, F., Harvey, V. L., Randall, C. E., Emmons, L., Lamarque, J. F., Hess, P., Orlando, J. J., Tie, X. X., Randel, W., Pan, L. L., Gettelman, A., Granier, C., Diehl, T., Niemeier, U., and Simmons, A. J.: Sensitivity of Chemical Tracers to Meteorological Parameters in the MOZART-3 Chemical Transport Model, J. Geophys. Res., 112, D03303, doi:10.1029/2008JD010739,2007.

Krol, M., Houweling, S., Bregman, B., van den Broek, M., Segers, A., van Velthoven, P., Peters, W., Dentener, F., and Bergamaschi, P.: The two-way nested global chemistry-transport zoom model TM5: algorithm and applications, Atmos. Chem. Phys., 5, 417432, 2005,

http://www.atmos-chem-phys.net/5/417/2005/.
Lefèvre, F., Brasseur, G. P., Folkins, I., Smith, A. K., and Simon, P.: Chemistry of the 1991-1992 stratospheric winter: three dimensional model simulations, J. Geophys. Res., 99, 8183-8195, 1994.

Lin, S. J. and Rood, R. B.: A fast flux form semi-Lagrangian transport scheme on the sphere, Mon. Weather Rev., 124, 2046-2070, 1996.

Louis, J.-F.: A parametric model of vertical eddy-fluxes in the atmosphere, Bound.-Lay. Meteorol., 17, 187-202, 1979.

Massart, S., Cariolle, D., and Peuch, V.-H.: Towards an improvement of the atmospheric ozone distribution and variability by assimilation of satellite data, C. R. Geosciences, 15, 1305-1310, 2005.

Ménard, R., Chabrillat, S., McConnel, J., et al.: Coupled chemical-dynamical data assimilation, ESA/ESTEC, Final Report, 451 pp., 2007.

Morcrette, J.-J., Boucher, O., Jones, L., Salmond, D. , Bechtold, P., Beljaars, A., Benedetti, A., Bonet, A., Kaiser, J. W., Razinger, M., Schulz, M., Serrar, S., Simmons, A. J., Sofiev, M., Suttie, M., Tompkins, A. M., and Untch, A.: Aerosol analysis and forecast in the ECMWF Integrated Forecast System. Part I: Forward modelling, J. Geophys. Res., 2009.

Mari, C., Jacob, D. J., and Bechtold, P.: Transport and scavenging of soluble gases in a deep convective cloud, J. Geophys. Res., 105, 22255-22267, 2000.

Ordóñez, C., Elguindi, N., Stein, O., Huijnen, V., Flemming, J., Inness, A., Flentje, H., Katragkou, E., Moinat, P., Peuch, V.-H., Segers, A., Thouret, V., Athier, G., van Weele, M., Zerefos, C. S., Cammas, J.-P., and Schultz, M. G.: Global model simulations of air pollution during the 2003 European heat wave, Atmos. Chem. Phys. Discuss., 9, 16853-16911, 2009, http://www.atmos-chem-phys-discuss.net/9/16853/2009/.

Park, M., Randel, W. J., Emmons, L. K., and Livesey, N. J.: Transport pathways of carbon monoxide in the Asian summer monsoon diagnosed from Model of Ozone and Related Tracers (MOZART), J. Geophys. Res., 114, D08303, doi:10.1029/2008JD010621, 2009.

Pozzoli L., Bey, I., Rast, J. S., Schultz, M. G., Stier, P., and Feichter, J.: Trace gas and aerosol interactions in the fully coupled model of aerosol-chemistry-climate ECHAM5HAMMOZ, PART I: Model description and insights from the spring 2001 TRACE-P experiment, J. Geophys. Res., 113, D07308, doi:10.1029/2007JD009007, 2008.

Randerson, J. T., van der Werf, G. R., Giglio, L., Collatz, G. J., and Kasibhatla, P. S.: Global Fire Emissions Database, Version 2 (GFEDv2), data set, Oak Ridge National Laboratory Distributed Active Archive Center, Oak Ridge, Tennessee, USA, idoi:10.3334/ORNLDAAC/834, available at: http://daac.ornl. gov/, 2006.

Rast, S., Schultz, M. G., Bey, I., van Noije, T., Aghedo, A. M., Brasseur, G. P., Diehl, T., Esch, M., Ganzeveld, L., Kirchner, I., Kornblueh, L., Rhodin, A., Röckner, E., Schmidt, H., Schröder, S., Schulzweida, U., Stier, P., Thomas, K., and Walters, S.: Interannual variability in tropospheric ozone over the 1980-2000 period: Results from the tropospheric chemistry general circulation model ECHAM5-MOZ, J. Geophys. Res., submitted, 26 November 2008.

Redler, R., Valcke, S., and Ritzdorf, H.: OASIS4 - a coupling software for next generation earth system modelling, Geosci. Model 
Dev. Discuss., 2, 797-843, 2009.

Russell, G. L. and Lerner, J. A.: A new finite-differencing scheme for the tracer transport equation, J. Appl. Meteorol., 20, 14831498, 1981.

Sander, S. P., Friedl, R. R., Golden, D. M., et al.: Chemical Kinetics and Photochemical Data for Use in Atmospheric Studies, Evaluation Number 14, JPL Publication 02-25, Jet Propulsion Laboratory, Pasadena, CA, USA, 2003.

Sander, S. P., Golden, D. M., Kurylo, M. J., et al.: Chemical Kinetics and Photochemical Data for Use in Atmospheric Studies, Evaluation Number 15, JPL Publication 06-02, Jet Propulsion Laboratory, Pasadena, CA, USA, 2006.

Schultz, M. G., Pulles, T., Brand, R., van het Bolscher, M., and Dalsøren, S. B.: A global data set of anthropogenic CO, NOx, and NMVOC emissions for 1960-2000, available at: http://retro. enes.org/data_emissions.shtml, 2009.

Singhl, H. B. and Jacob, D.: Future directions: Satellite observations of tropospheric chemistry, Atmos. Environ., 34(25), 43994401, 2000.

Tiedtke, M. A: comprehensive mass flux scheme for cumulus parameterization in large-scale models, Mon. Weather. Rev., 117(8), 1779-1800, 1989.
Tilmes, S. and Zimmermann J.: Investigation on the spatial scales of the variability in measured near-ground ozone mixing ratios, Geophys. Res. Lett., 25(20), 3827-3830, 1998.

van der Werf, G. R., Randerson, J. T., Giglio, L., Collatz, G. J., Kasibhatla, P. S., and Arellano Jr., A. F.: Interannual variability in global biomass burning emissions from 1997 to 2004, Atmos. Chem. Phys., 6, 3423-3441, 2006, http://www.atmos-chem-phys.net/6/3423/2006/.

Williamson, D. L. and Rash, P. J.: Two-dimensional semi lagrangian transport with shape-preserving interpolation, Mon. Weather Rev., 117, 102-129, 1989.

Zhang, G. J. and McFarlane, N. A.: Sensitivity of climate simulations to the parameterization of cumulus convection in the Canadian climate centre general circulation model, Atmos. Ocean, 33, 407-446, 1995.

Zhang, Y.: Online-coupled meteorology and chemistry models: history, current status, and outlook, Atmos. Chem. Phys., 8, 28952932, 2008,

http://www.atmos-chem-phys.net/8/2895/2008/. 